Robert J. Byrick MD FRCP(C), Julia O. Ycas RRT, Tomas A. Salemo MD FRCS

\title{
Tracheomotor response to cardiopulmonary bypass: influence of lung deflation and cardiac distension
}

The pressure within the water-filled cuff of an endotracheal tube (PTE) was used as a measure of tracheal smooth muscle tone in ten patients undergoing cardiopulmonary bypass (CPB). Pulmonary artery pressure $(P P A)$ and left atrial pressure ( $P L A)$ were also monitored. Institution of $C P B$, with acute reduction of pulmonary blood flow and lung deflation, caused no significant change in PrE.

Crystalloid cardioplegic administration without left ventricular decompression (VENT) resulted in statistically significant increases of $P_{P A}($ from $1.33 \pm 0.15$ to $1.88 \pm$ $0.2 \mathrm{kPa})(p<0.05)$ and of $P_{L A}$ (from $1.2 \pm 0.11$ to $2.2 \pm 0.31 \mathrm{kPa})(p<0.05)$. Coincident with these changes a statistically significant increase in PTE (from $4.95 \pm 0.21$ to $5.24 \pm 0.27 \mathrm{kPa})(p<0.05)$ was detected. This increase in $P$ TE was significantly greater than the small random variations noted in $P \mathrm{TE}$ prior to cardioplegic infusion with constant $P_{L A}$ and $P_{P A}$. Thus, minimal tracheomotor constriction in response to car-

\section{Key words}

LUNG: airway tone, inflation; HEART: distension; SURGERY, CARDIOVASCULAR: cardiopulmonary bypass, cardioplegia.

From the Department of Anaesthesia and the Division of Cardiovascular surgery, University of Toronto, St. Michael's Hospital, Toronto, Canada.

Address correspondence to: Dr. R. Byrick, Dept. of Anaesthesia, St. Michael's Hospital, 30 Bond Street, Toronto, Canada, M5B 1W8.

Supported by a grant from the Ontario Heart Foundation, Canada. dioplegia administration occurred. Larger increases in $P_{T E}$ were noted during cardiac compression suggesting that the water-filled cuff could have detected larger increases if they had occurred. These transient changes do not reflect clinically detectable increases in airway resistance at the termination of $C P B$ when lung ventilation is started. Neither of these two physiological stimuli, lung deflation or cardioplegia administration, cause clinically significant increases of large ainway tone during $C P B$.

Life-threatening bronchospasm has been reported during cardiopulmonary bypass (CPB). ${ }^{1}$ Although the aetiology is unknown, severe air-trapping can prevent weaning from extra-corporeal circulation. ${ }^{\prime}$ Human airways remain reactive during $\mathrm{CPB}^{2}$ and can respond to physiologic stimuli. ${ }^{3}$ Also, central airway resistance has been shown to increase when the lungs are deflated or the left artrial pressure is increased in animal experiments. ${ }^{4.5}$ Jones et al. ${ }^{6}$ documented that pulmonary venous congestion increased airway resistance and 'closing volume.' This airway closure was attributed to a vagallymediated reflex. During CPB, Lloyd ${ }^{7}$ induced reflex tracheal constriction by distending the left heart and inducing mild pulmonary congestion in dogs.

The purpose of this study was to determine whether a tracheomotor response to CPB with lung collapse occurred clinically, and to assess the airway response to left heart distension which can accompany cardioplegic administration.

\section{Methods}

We studied ten patients (weight $63.4-108 \mathrm{~kg}$ ) 
undergoing elective coronary artery bypass surgery for treatment of incapacitating angina. None of these patients had a history of congestive heart failure. A history of smoking was obtained in six of the ten patients, and three had clinical evidence of chronic obstructive lung disease. No patient had a history of asthma or hayfever.

This study was approved by the Human Experimentation Committee of the University of Toronto who agreed that no formal patient consent was required.

Preoperative medications, including propranolol, nifedipine, isosorbide dinitrate and nitroglycerin, were continued up to the morning of surgery. Anaesthetic management was standardized. All patients were premedicated with perphenazine $5 \mathrm{mg}$ and morphine $10-15 \mathrm{mg}$ intramuscularly. Anaesthesia was induced with fentanyl $\left(50 \mu \mathrm{g} \cdot \mathrm{kg}^{-1}\right)$ and diazepam (10-20 mg) intravenously. Pancuronium $\left(0.15 \mathrm{mg} \cdot \mathrm{kg}^{-1}\right)$ was used to provide muscle relaxation for tracheal intubation. Fentanyl was administered as required for analgesia; no anaesthetic vapour was used. All patients were mechanically ventilated $\left(\mathrm{FlO}_{2}=1.0\right)$ at a rate of $6-11$ breaths per minute to maintain normocapnia.

Systemic arterial pressure (BP) was monitored continuously using a left radial artery cannula (\#20 gauge). Pulmonary arterial pressure (PPA) was monitored using a 7 Fr. triple lumen Swan-Ganz catheter. Prior to institution of CPB a $16 \mathrm{Fr}$. catheter was inserted into the left atrium (LA) via the right superior pulmonary vein for measurement of PLA. Each pressure was recorded with a Bentley Trantec model 800 transducer connected to a Gould recorder (ES $1000 \mathrm{~B}$ ).

A Shiley $9 \mathrm{~mm}$ low-pressure, cuffed endotracheal tube was used for each patient. It was modified such that the 'pilot balloon' was eliminated and the tubing was connected directly to a pressure transducer positioned at the same height as the patient's trachea. The cuff was filled with sterile water prior to each study ensuring that no air bubbles remained. After intubation, water was added to the cuff until a clinical seal of the airway to positive pressure ventilation was noted. Once this volume had been determined no additional water was added or removed from the cuff for the duration of the study. The mean volume of water used was $9.1 \pm 0.6 \mathrm{ml}$. No local anaesthetic spray or lubri- cant was used on the cuff or at intubation. Tracheal cuff pressure (PTE) was monitored continuously ${ }_{9}^{8}$ along with $B P, P L A$ and $P P A$, on the recorder.

Extracorporeal circulation was established after heparinization ( 300 units $/ \mathrm{kg}$ ) using a Travenol polypropylene membrane oxygenator. Blood for constant-flow systemic perfusion was obtained from a single cannula in the right atrium and was returned from the oxygenator through a standard Morris aortic cannula. The oxygenator was primed with $2,000 \mathrm{ml}$ of lactated Ringer's solution and mannitol (10 gms). No corticosteroids were administered to any patient. After initiation of CPB, with exclusion of pulmonary blood flow, mechanical ventilation of the lungs ceased and the endotracheal tube was opened to atmosphere as the lungs collapsed. No positive airway pressure was present during CPB. Systemic hypothermia $\left(28^{\circ} \mathrm{C}\right)$ was induced after a two-minute control (normothermia) period on CPB with lung deflation during which time baseline pressures were recorded and arterial blood samples were obtained and analyzed for $\mathrm{PO}_{2}$, $\mathrm{PCO}_{2}$ and $\mathrm{pH}$.

The aorta was then cross-clamped and cold $\left(4^{\circ} \mathrm{C}\right)$ crystalloid cardioplegic solution* was infused into the aortic root via a 14 gauge needle after systemic cooling had begun. ${ }^{9}$

To assess the random variation in the measurement of PTE during CPB (with constant low PPA and PLA values), we examined a segment of the continuous recording prior to cardioplegic administration in each patient. The duration of the recording was of the same length of time as the subsequent cardioplegic infusion. The maximal change in PTE during this segment was then compared to maximal changes in PTE documented during cardioplegic administration using a paired t-test.

During infusion of cardioplegia under bag pressure of $40 \mathrm{kPa}$, the LA and left ventricle (LV) were occasionally noted to distend as this solution will either perfuse the ischaemic coronary vasculature or pass into the LV through a functionally regurgitant aortic valve. Also, during $\mathrm{CPB}$ and cardioplegic administration, bronchial arterial flow continued

\footnotetext{
*Cardioplegia solution contained $20 \mathrm{mEq} \cdot \mathrm{L}^{-1}$ of potassium chloride, $3 \mathrm{mEq} / \mathrm{L}$ of magnesium sulphate, $2 \mathrm{mEq} / \mathrm{L}$ tromethamine, and $27 \mathrm{mEq} / \mathrm{L}$ sodium chloride in five per cent dextrose in water.
} 


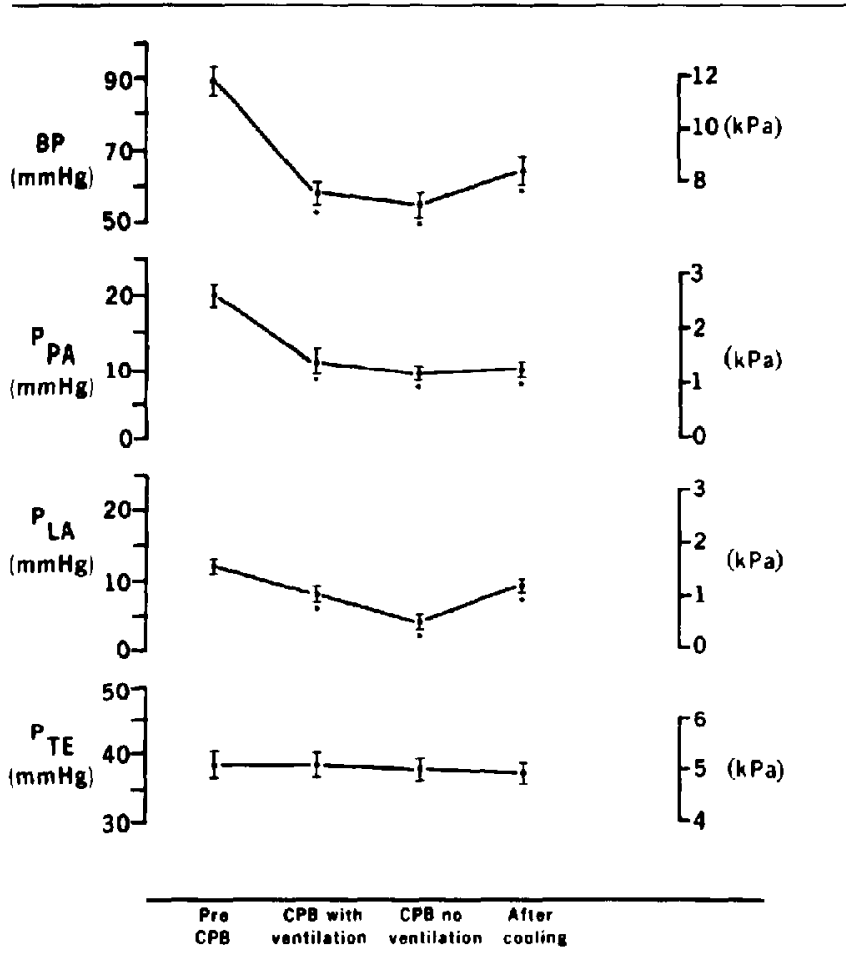

FIGURE I BP, PLA, PPA, and PTE before and after institution of CPB, subsequent discontinuation of ventilation with lung deflation and systemic hypothermia. ${ }^{*}=$ significant change from pre CPB level $(\mathrm{p}<0.05)$.

via the systemic circulation, and PPA may increase as the pulmonary vasculature becomes engorged without a functional decompression or 'vent.'

After $1,000 \mathrm{ml}$ of cardioplegia had been infused (titrated to keep the septal myocardial temperature at less than $10^{\circ} \mathrm{C}$ ) the cardioplegic needle in the aortic root was used as a vent. ${ }^{8}$ This technique has been shown to effectively decompress the left heart and reduce $L V$ pressure."

A portable chest radiograph was examined postoperatively to determine the location of the endotracheal tube cuff. The distance from the carinal bifurcation of the trachea to the distal radio-opaque marker of the endotracheal tube was measured.

Statistical evaluation of the data was performed using Student's paired t-test and two-way analysis of variance followed by Dunnett's multiple range test for sequential data. All data are reported as mean \pm standard error of the mean.

\section{Results}

The institution of CPB with lung deflation was not associated with any significant change in PTE (Fig. 1). Mean BP, PPA and PLA decreased significantly with exclusion of the pulmonary blood flow during initiation of $\mathrm{CPB}$ with continued ventilation. When the lungs were deflated with cessation of ventilation (Fig. 1) no further significant change in BP, PPA or PTE was observed, although PLA continued to fall from pre-CPB levels (Fig. 1).

Gradual increases in PPA and PLA were observed at a variable time period after cardioplegic infusion. Transient and sudden increases in PPA and PLA superimposed on these more gradual increases were noted in conjunction with surgical manipulation and manual cardiac compression (Fig. 2). These sudden and transient increases of intravascular pressures with manipulation have been previously reported. ${ }^{10.11}$ 


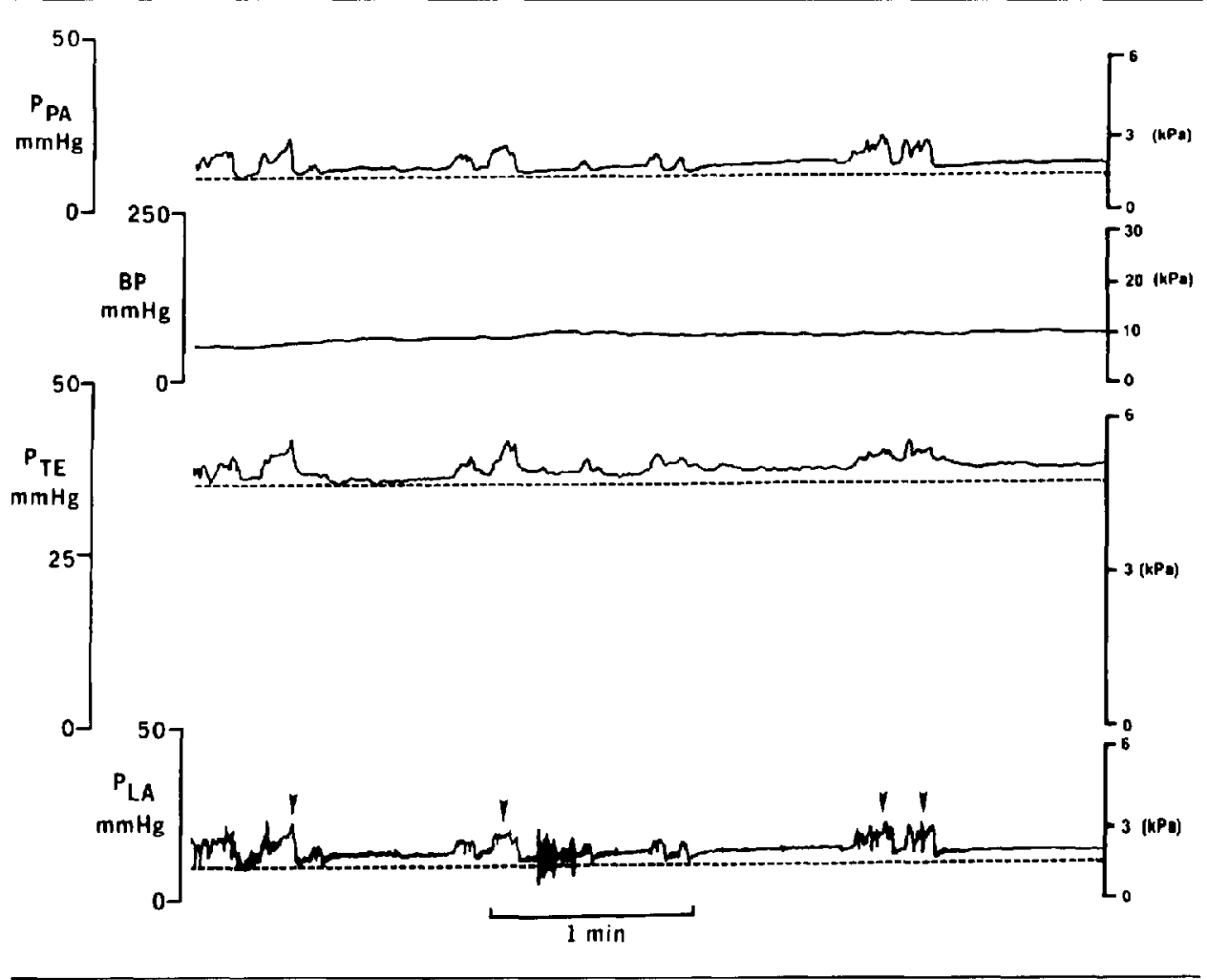

FIGURE 2 A representative trace of $B P, P P A, P L A$ and $P$ TE during cardioplegia infusion. Small, gradual increases of PPA, PLA and PTE from baseline levels (hatehed lines) are noted with superimposed acute increases in pressures when manual cardiac compression occurred (arrows).

In these ten patients a statistically significant increase in PPA, PLA and PTE occurred after infusion of cardioplegia (Table I). PTE increased from $4.95 \pm 0.21$ to $5.24 \pm 0.27 \mathrm{kPa}(p<0.05)$ during cardioplegia administration (Table I).

The duration of cardioplegic infusion ranged from two to eight minutes. At the end of this period PTE had increased significantly. Because of the small magnitude of the PTE increase with cardioplegia alone (Table I) which averaged only $0.29 \pm$ $0.08 \mathrm{kPa}$, the latency period after increased $\mathrm{PPA}_{\mathrm{A}}$ and PLA until the PTE response was recognized could not be accurately assessed. However, when the LV was manually compressed PLA and PPA increased instantaneously (Fig. 2). PTE also increased in each case with this increase in PPA and PLA. With manual cardiac compression PLA increased from $1.93 \pm 0.09$ to $28.1 \pm 0.4 \mathrm{kPa}$. Coincident with this increase in PLA, Pre increased significantly $(p<0.001)$ from $5.13 \pm 0.12$ to $5.36 \pm 0.12 \mathrm{kPa}$ $(n=10)$.

Small random changes in PTE during CPB prior to each cardioplegic administration were $-0.07 \pm$ $0.09 \mathrm{kPa}$. This was used as a measure of the random variation of PTE with constant, Jow PLA and PPA. This value was compared to the change in PTE during cardioplegic administration (and increased PPA and PLA). The very small increase of PTE during cardioplegia (mean $0.29 \pm 0.08 \mathrm{kPa}$ ) was significantly greater than these random changes in PTE prior to cardioplegic arrest in the ten patients $(p<$ 0.005 ). No significant difference was found between the changes in PTE with cardioplegia in smokers $(n=6)$ and non-smokers $(n=4)$.

No consistent change in mean arterial blood pressure (BP) was noted during cardioplegic infu- 
TABLE 1 Mean \pm SEM of haemodynamic parameters during cardioplegia (CPS) $(n=10)$

\begin{tabular}{|c|c|c|c|c|c|c|}
\hline & \multirow[b]{2}{*}{ Control } & \multicolumn{4}{|c|}{ Cardioplegia infusion } & \multirow[b]{2}{*}{ End CPS } \\
\hline & & $30 \mathrm{sec}$. & $60 \mathrm{sec}$. & $90 \mathrm{sec}$. & $120 \mathrm{sec}$. & \\
\hline \multirow[t]{2}{*}{ PLA } & $1.2 \pm 0.11$ & $1.79 \pm 0.25^{*}$ & $2.04 \pm 0.27^{*}$ & $2.03 \pm 0.28^{*}$ & $2.24 \pm 0.39 *$ & $2.2 \pm 0.3 l^{*}$ \\
\hline & $(9 \pm 0.8)$ & $\left(13.4 \pm(.9)^{*}\right.$ & $(15.3 \pm 2)^{*}$ & $(15.2 \pm 2.1)^{*}$ & $(16.8 \pm 2.9)^{*}$ & $(16.5 \pm 2.3)^{*}$ \\
\hline \multirow[t]{2}{*}{ PPA } & $1.33 \pm 0.15$ & $1.73 \pm 0.17^{*}$ & $1.89=0.2^{*}$ & $1.83 \pm 0.16^{*}$ & $1.83 \pm 0.16^{*}$ & $1.88 \pm 0.2^{*}$ \\
\hline & $(9.97 \pm 1.1)$ & $(13 \pm 1.3)^{*}$ & $(14.2 \pm 1.5)^{*}$ & $(13.7 \pm 1.2)^{*}$ & $(13.7 \pm 1.2)^{*}$ & $(14.1 \pm 1.5)^{*}$ \\
\hline \multirow[t]{2}{*}{ PтE } & $4.95 \pm 0.21$ & $5.05 \pm 0.21$ & $5.07 \pm 0.21$ & $5.08 \pm 0.23^{*}$ & $5.09 \pm 0.23 *$ & $5.24 \pm 0.27 *$ \\
\hline & $(37.1 \pm 1.6)$ & $(37.9 \pm 1.6)$ & $(38.0 \pm 1.6)$ & $(38.1 \pm 1.7)^{*}$ & $(38.2 \pm 1.7)^{*}$ & $(39.3 \pm 2.0)^{*}$ \\
\hline \multirow[t]{2}{*}{$\mathrm{BP}$} & $8.66 \pm 0.53$ & $8.93 \pm 0.67$ & $8.8 \pm 0.63$ & $9 \pm 0.84$ & $9.3 \pm 0.97$ & $10.0 \pm 0.99^{*}$ \\
\hline & $(65 \pm 4)$ & $(67 \pm 5.0)$ & $(66.0=4.7)$ & $(67.5 \pm 6.3)$ & $(70.0 \pm 7.3)$ & $(75.0 \pm 7.4)^{*}$ \\
\hline
\end{tabular}

Values (mean \pm SEM of BP, PPA, PLA and PTE) at intervals after CPS administration. Measurements are expressed in kPa, with $\mathrm{mmHg}$ in parentheses. The END value was measured at the termination of CPS infusion. *Denotes significant change from control $(\mathrm{p}<0.05)$.

sion (Table I). The mean temperature of arterial blood measured one minute after cardioplegic infusion was $27.2 \pm 0.8^{\circ} \mathrm{C}$ (range $24-32^{\circ} \mathrm{C}$ ). There was not significant relationship between the blood temperature and PTE response to increases in PLA and PPA. The values of $\mathrm{PaO}_{2}, \mathrm{PaCO}_{2}$ and $\mathrm{pH}$ prior to cardioplegic administration and at the one- and three-minute interval after cardioplegic administration are presented in Table II. $\mathrm{PaCO}_{2}$ did not change during infusion whereas $\mathrm{PaO}_{2}$ decreased significantly at both one and three minutes with a mild acidemia evident at only the three-minute measurement.

A portable chest radiograph showed that the distal radio-opaque marker on the endotracheal tube was located between 23 and $63 \mathrm{~mm}$ above the carinal bifurcation. All cuffs were located at least partially in the extrathoracic trachea on chest radiograph and since all studies were performed after thoracotomy the influence of pleural pressure changes was negligible.

\section{Discussion}

Transient lung inflation has been shown to cause tracheal dilation in anaesthetized dogs. ${ }^{2,13}$ Whether lung deflation during $\mathrm{CPB}$ results in tracheomotor constriction has never been assessed because ventilation ceases, making the conventional measurement of airway resistance impossible. We found no evidence of any significant tracheomotor response to either the institution of $\mathrm{CPB}$ with exclusion of pulmonary blood flow or lung deflation (Fig. 1). General anaesthesia has been shown to selectively depress reflex bronchoconstictor responses, ${ }^{14}$ and this may account for the lack of a reflex tracheal constiction to lung deflation. Severinghaus et al. ${ }^{15}$ postulated that regional increases in airway smooth muscle tone occur when perfusion decreases to maintain ventilation:perfusion matching. Total diversion of pulmonary blood flow at the initiation of CPB did not increase tracheomotor tone in anaesthetized humans in our study.

Reflex tracheal constriction has also been shown to result from left heart distension in animal models. ${ }^{7}$ The PTE increases documented during cardioplegic infusion (Table I) were small; however, statistically they were significantly greater than random PTE variations noted in the same patients with constant PLA and PPA prior to cardioplegic administration.

A significant relationship between intrathoracic tracheal circumference and extrathoracic tracheal cuff pressure (PTE) has been demonstrated in dogs. ${ }^{8}$ Assuming that a similar relationship is also present in man, our data suggest that very minimal tracheal constriction normally occurs during cardioplegia administration. We could not quantify the absolute magnitude of the circumference change reflected by the small PTE changes after cardioplegia. There is no doubt that these tracheal circumference changes resulting from cardioplegic administration were not clinically detectable by conventional techniques measuring airway resistance or dynamic compliance. Lloyd ${ }^{7}$ made similar observations in animal experiments.

Total airway resistance increases considerably at low lung volumes ${ }^{12}$ due to an increase in resistance of central airways. If this occurred in our patients, 
the increased PLA and PPA resulting from cardioplegic infusion might not further increase tracheomotor tone. We detected no increase in PTE with the institution of CPB and lung deflation (Fig. 1) and the larger increase in PTE with cardiac manipulation (Fig. 2) suggests that the trachea could have constricted further during cardioplegic infusion.

Sustained large increases of PLA and PPA are rare even without venting procedures. ${ }^{10,11}$ The small magnitude of the PTE increase may simply reflect the small magnitude of PLA and PPA increases found clinically. It is possible that larger increases of PTE might have been produced if PPA and PLA had been greater.

Other potential causes of the small magnitude of PTE response are anaesthetic state ${ }^{14}$ and hypothermia. Lloyd ${ }^{7}$ suggested that LA and LV distension did not cause significant alterations of airway resistance and dynamic compliance, although tracheomotor responses similar to those demonstrated in our patients were described. Left heart distension in his animal model ${ }^{7}$ increased tracheal tension; whereas pulmonary congestion increased tracheal tension in some dogs but decreased it in others. All of these effects were eliminated by vagotomy. Thus, reflex tracheal constriction from left heart distension may be reduced by a caexisting dilator reflex from pulmonary congestion. This balance may also have contributed to the small magnitude of the PTE changes observed in our patients.

Woolcock et al ${ }^{16}$ have shown that changes in airway tone mediated by vagal stimulation occur in both central and peripheral airways. Whether smaller airways constrict in response to pulmonary artery exclusion and lung deflation remains conjectural. The changes in PTE observed in our study could not be secondary to altered chest wall compliance $^{17}$ since the chest was open and the surrounding pleural pressure was atmospheric throughout the study. The cuff was located in the trachea of these patients at variable levels, suggesting that the PTE response is not a localized phenomenon but is present throughout the trachea at least. Because the endotracheal tube was open to atmosphere, any mechanical compression of the airway caused by manual compression of the heart would not increase PTE.

Borst et al. ${ }^{15}$ measured airflow resistance and dynamic compliance in dogs during right ventricu-
TABLE II Data from arterial blood gas analysis during CPB

\begin{tabular}{lcll}
\hline & & \multicolumn{2}{l}{ During Cardioplegia } \\
\cline { 3 - 4 } Time: & Prior to cardioplegia & 1 min & $3 \mathrm{~min}$ \\
\hline $\mathrm{pH}$ & $7.47 \pm 0.02$ & $7.44 \pm 0.01$ & $7.42 \pm 0.01 *$ \\
$\mathrm{PaCO}_{2}$ & $37.1 \pm 2.0$ & $36.9 \pm 1.7$ & $38.6 \pm 1.5$ \\
$\mathrm{PaO}_{2}$ & $213.8 \pm 27.9$ & $138.4 \pm 18.2 *$ & $140.1 \pm 17.2^{*}$ \\
\hline
\end{tabular}

*Statistically significant change $(p<0.05)$ from the control value prior to cardioplegia administration. $(n=10)$

lar bypass and showed that compliance was reduced 80 per cent at a LA pressure of $5.3 \mathrm{kPa}$. Jones et al. ${ }^{6}$ used reversible mitral valve obstruction and increases of PLA from 0.26 to $2 \mathrm{kPa}$ significantly reduced dynamic compliance and increased airway resistance as well as increasing 'closing volume.' Vagotomy returned these values to normal ${ }^{6}$ suggesting a reflex basis for the airway constriction. These animal studies ${ }^{4,6,7}$ indicate that mild pulmonary congestion and LA distension cause small, reversible changes in airway tone. Our data suggest that the PPA and PLA found during uncomplicated CPB are not associated with clinically important increases in tracheomotor tone.

There are many similarities between our clinical situation (CPB) and the experimental protocol used by Lloyd ${ }^{7}$ in dogs. However, for ethical reasons we could not alter the duration of cardioplegic infusion or increase the PLA for a prolonged period of time to levels used in the animal studies ${ }^{4.6 .7}$ Nor did we isolate the effects of left heart distension from pulmonary vascular engorgement, cardioplegic infusion or acid-base derangement (Table II). The cardioplegic solution itself could stimulate myocardial receptors which could initiate large airway reflexes. The change in $\mathrm{pH}$ (Table II) and decrease of $\mathrm{PaO}_{2}$ were statistically significant and could have contributed to the small increases in tracheal tone (Fig. 3), although haemoglobin oxygen saturation would not be affected by this reduction in $\mathrm{PaO}_{2}$ (Table II).

In conclusion, we found no evidence that postCPB 'brochospasm" is related to the initiation of CPB with lung deflation or to left heart distension during cardioplegia administration, although both of these physiologic stimuli have been associated with increased airway smooth muscle tone in animal experiments. This is not meant to imply that the anaesthetist should not monitor PPA during 
CPB when a PA catheter is in place. Since PPA increases simultaneously with PLA during left heart distension (Table I) and manual manipulation (Fig. 2), the clinician may be able to warn the surgical team of left heart distension during $\mathrm{CPB}$ which can result from functional aortic regurgitation and reduce subendocardial perfusion.

\section{Acknowledgements}

The authors thank Patricia Slusarenko and Lori MacKay for their valuable assistance, and the Ontario Heart Foundation for their financial support.

\section{References}

1 Shiroka A, Rah KH, Kennan RL. Brochospasm during cardiopulmonary bypass. Anesth Analg 1982; 61: 538-40.

2 Patterson RW, Sullivan SF, Malm JR, Bowman FO, Papper EM. Effect of airway hypocapnia on mechanics of breathing during cardiopulmonary bypass. Circulation 1967; 35, 36 (Suppl I): 212-6.

3 Meloche $R$, Norlander $O$, Norden I, Herzog $P$. Effects of carbon dioxide and halothane on compliance and pulmonary resistance during cardiopulmonary bypass. Scand J Thorac Cardiovase Surg 1969; 3: 69-78.

4 Hogg JC, Agarawal JB, Gardiner AJ, Palmer WH, Macklem PT. Distribution of airway resistance with developing pulmonary edema in dogs. J Appl Physiol 1972; 32: 20-4.

5 Briscoe WA, Dubois $A B$. The relationship betwecn airway resistance, airway conductance and lung volume in subjects of different age and body size. $J$ Clin Invest 1958; 37: 1279-85.

6 Jones JG, Lemon $R$, Graf $P D$. Changes in airway calibre following pulmonary venous congestion. Br J Anacsth 1978; 50: 743-51.

7 Lloyd TC. Reflex effects of left heart and pulmonary vascular distension on airways of dogs. J Appl Physiol 1980; 49: 620-6.

8 Byrick RJ, Hobbs EG, Kay JC. Extrathoracic cuff pressure reflects changes of intrathoracic large airway circumference. Anesth Anaig 1982; 61 : 693-8.

9 Harlan BJ, Kyger ER, Reul GJ, Cooley DA. Needle suction of the aorta for left heart decompression during aortic cross-clamping. Ann Thorac Surg 1977; 23: 259-60.
10 Zwart HHJ, Brainard JZ, DeWall RA. Ventricular fibrillation without left ventricular venting. Ann Thorac Surg 1975; 20: 418-23.

11 Salerno TA, Charrette EIP. Elimination of venting in coronary surgery. Ann Thorac Surg 1979; 27: 340-3.

12 Macklem PT, Mead J. Resistance of central and peripheral airways measured by a retrograde catheter. J Appl Physiol 1967; 22: 395-401.

13 Widdicombe JG, Nadel JA. Reflex effects of lung inflation of tracheal volume. J Appl Physiol 1963; 18: 681-6.

14 Holtzman MJ, Hahn JA. Sedative effect of general anesthetics on reflex bronchoconstrictor responses in dogs. J Appl Physiol 1982; 53: 126-33.

15 Severinghaus $J W$, Swenson $E W$, Finley $T W$, Laregala $M T$, Williams $J$. Unilateral hypoventilation produced in dogs by occluding onc pulmonary artery. J Appl Physiol 1961; 16: 53-60.

16 Woolcock AJ, Macklem PT, Hogg JC, et al. Effect of vagal stimulation on central and peripheral airways in dogs. J Appl Physiol 1069; 26: 806-13.

17 Segal BJ. Tracheal constriction or decreased lungthorax compliance from opiates. (Letter) Anesthesiology $1979 ; 51: 183$.

18 Borst HG, Berlund E, Whittengerger JL, Mead J. $M c G r e g o r M$, Collier $C$. The effect of pulmonary vascular pressures on the mechanical properties of anesthetized dogs. J Clin Invest 1957; 36: 1708-14 
Résumé

La pression a l'intérieur du ballonnet du tube endotrachéal rempli d' eau (PTE) a été utilisée comme mesure du ronus des muscles lisses extrathoraciques de la trachée chez dix patients devant subir une circulation extracorporelle (CPB). La pression de l'artère pulmonaire $\left(P P_{A}\right)$ et la pression de l'oreillette gauche $(P L A)$ ont eté mesurées. $L$ 'initiation de la CEC, avec la réduction aiguë du flot sanguin pulmonaire et la déflation des poumons, n'a pas provoqué de changement significatif de la PTE.

L'administration de cardioplégie aux cristalloïdes sans décompression du ventricule a occasionné une augmentation significative de la PPA (de $1.33 \pm 0.15 \dot{a}$ $1.88 \pm 0.2 \mathrm{KPa})(p<0.05)$ et de la $P_{L A}($ de $1.2 \pm 0.11 \dot{a}$ $2.2 \pm 0.31 \mathrm{KPa})(p<0.05)$. Correspondant à ces changements, on a observé une augmentation statistiquement significative de la PTE (de $4.95 \pm 0.21$ à $5.24 \pm$ $0.27 \mathrm{KPa})(p<0.05)$. Cette augmentation de la PTE était significativement plus grande que les petites variations observées au hasard et notées dans la PTE avant la perfusion de la solution de cardioplégie avec une $P_{L A}$ et une PPA constantes. Ainsi une constriction trachémotrice très minime en répose à l'administration de la cardioplégie est survenue. De plus grandes augmentations dans la PTE ont été norées lors de la compression cardiaque suggérant que le ballonnet rempli d' eau aurait pu détecter de plus grandes augmentations si elles étaient survenues. Ces changements transitoires ne reflètent pas une augmentation cliniquement détectable dans la résistance des voies aériennes à la cessation de la CEC quand la ventilation est réinstallée. Aucun de ces deux stimulus physiologiques lla déflation des poumons ou l'administration de la cardioplégie) ne provoque une augmentation significative clinique des voies aériennes hautes pendant la $C E C$. 